\title{
Análise probabilística de ocorrência de incompatibilidade da qualidade da água com 0 enquadramento legal de sistemas aquáticos - estudo de caso do rio Pariquera-Açu (SP)
}

\author{
Probabilistic analysis of the occurrence of incompatibility of the water \\ quality with the legal framework of aquatic systems - case study of \\ Pariquera-Açu River (SP, Brazil)
}

\author{
Davi Gasparini Fernandes Cunha \\ Engenheiro Ambiental pela Escola de Engenharia de São Carlos da Universidade de São Paulo (EESC-USP). \\ Doutorando em Engenharia Hidráulica e Saneamento da EESC-USP \\ Maria do Carmo Calijuri \\ Bióloga pela Universidade Federal de São Carlos (UFSCar). Mestre em Ecologia e Recursos Naturais pela UFSCar. \\ Doutora em Engenharia Hidráulica e Saneamento pela EESC-USP. \\ Professora Titular do Departamento de Hidráulica e Saneamento da EESC-USP
}

\section{Resumo}

Embora relativamente comuns no Brasil, programas de monitoramento da qualidade da água frequentemente não transformam os resultados em elementos que norteiem o poder público para a recuperação dos sistemas aquáticos. Assim, a presente pesquisa teve por objetivo discutir a utilização das curvas probabilísticas de incompatibilidade da qualidade da água com o enquadramento legal dos corpos de água como ferramenta complementar ao monitoramento. As probabilidades de inconformidade com a resolução CONAMA 357/05 (Classe 2) para o rio Pariquera-Açu (SP) em 2007 foram de 35, 8, 44, 1, 0, 0 e 0\%, respectivamente para oxigênio dissolvido, turbidez, fósforo, nitrogênio amoniacal, nitrito, nitrato e clorofila-a. Concluiu-se que o grau de condensação de informações gerado pelas curvas probabilísticas representa uma contribuição para a gestão da qualidade de água

Palavras-chave: curvas probabilísticas; enquadramento dos corpos de água; monitoramento ambiental; resolução CONAMA 357/05; vale do rio Ribeira de Iguape.

\begin{abstract}
Although relatively common in Brazil, water quality monitoring programs usually do not organize the results in a way that they are able to guide local authorities for reclamation of aquatic systems. Therefore, this research aimed to discuss the use of probabilistic curves of water quality incompatibility with Brazilian legal framework of water bodies as a complementary tool for monitoring. The incompatibility probabilities with CONAMA 357/05 (framework for Class 2) for PariqueraAçu river (São Paulo, Brazil) were 35, 8, 44, 1, 0, 0 and 0\%, respectively, for dissolved oxygen, turbidity, phosphorus, nitrogen-ammonia, nitrite, nitrate and chlorophyll-a. We concluded that the condensation level of information achieved by probabilistic curves represents an important contribution for management of quality of the water.
\end{abstract}

Keywords: probabilistic curves; framework of water bodies; environmental monitoring; CONAMA 357/05; Ribeira de Iguape river basin. 


\section{Introdução}

A adequada gestão dos recursos hídricos é tema recorrente na atualidade, uma vez que a disponibilidade da água, em especial para fins nobres como o abastecimento humano tem sofrido restrições significativas em função do comprometimento de seus aspectos de qualidade e quantidade. Nesse sentido, a resolução CONAMA 357, de 17 de março de 2005 (Brasil, 2005), que "dispõe sobre a classificação dos corpos de água e diretrizes ambientais para o seu enquadramento (...)", pode ser vista como um importante instrumento da Política Nacional dos Recursos Hídricos - lei no 9.433/1997 - Brasil (1997). O monitoramento dos ecossistemas aquáticos brasileiros deve, preferencialmente, promover uma comparação entre a condição ambiental observada, por meio das variáveis da água, e a situação desejável, norteada pela resolução CONAMA 357/05, de acordo com a classe em que o ambiente aquático foi enquadrado.

O monitoramento ambiental, portanto, possui relevante importância por permitir, em longo prazo, o conhecimento das tendências de evolução da qualidade das águas, por meio da quantificação de variáveis físicas, químicas e biológicas, e viabilizar, desse modo, o amplo diagnóstico ambiental da bacia hidrográfica estudada. Esse diagnóstico, seja de sistemas de água doce ou de água salobra/salgada, pode permitir a avaliação das respostas dos ambientes aquáticos (em termos espaciais e temporais) aos impactos antrópicos na sua área de drenagem ou de influência.

Entretanto, os programas de monitoramento, na maioria dos casos, limitam-se a apresentar significativa quantidade de dados sem, no entanto, sistematizá-los de modo que possam orientar planos de gestão da qualidade da água e de gerenciamento dos recursos hídricos. Yabe e Oliveira (1998) e Groppo (2005), por exemplo, apresentaram um conjunto de dados resultantes do monitoramento de sistemas aquáticos com o objetivo precípuo de caracterizá-los e apresentar uma análise de tendências temporais. Araujo (1998) e Clement e Thas (2007), por sua vez, buscaram uma exploração adicional dos resultados de monitoramento e propuseram, respectivamente, uma adaptação do índice de integridade biótica (IIP) para o rio Paraíba do Sul, Rio de Janeiro, e um modelo matemático para avaliar a presença de tendências ou o efeito de determinadas ações sobre a qualidade da água de sistemas lóticos da Europa. Norris e Hawkins (2000) trouxeram uma interessante

Tabela 1 - Limites superiores ou inferiores, dependendo do caso, de algumas variáveis da água para ambientes aquáticos de Classe 2 (resolução CONAMA 357/05)

\begin{tabular}{lcc} 
Variável & \multicolumn{2}{c}{ Limite para rios de Classe 2} \\
\cline { 2 - 3 } & Natureza & Valor \\
\hline Oxigênio dissolvido & Inferior & $5 \mathrm{mg} \cdot \mathrm{L}^{-1}$ \\
\hline Turbidez & Superior & $100 \mathrm{UT}$ \\
\hline Fósforo total & Superior & $0,1 \mathrm{mg} \cdot \mathrm{L}^{-1}$ \\
Nitrogênio amoniacal & Superior & $3,7 \mathrm{mg} \cdot \mathrm{L}^{-1}(\mathrm{pH} \leq 7,5)$ \\
\hline Nitrito & Superior & $1.000 \mu \mathrm{g} \cdot \mathrm{L}^{-1}$ \\
Nitrato & Superior & $10 \mathrm{mg} \cdot \mathrm{L}^{-1}$ \\
\hline Clorofila-a & Superior & $30 \mu \mathrm{g} \cdot \mathrm{L}^{-1}$ \\
\hline
\end{tabular}

discussão sobre o uso de modelos preditivos ou multimétricos e quais as vantagens de cada método para monitorar a qualidade da água de rios. Em síntese, a abordagem preditiva baseia-se na comparação entre a composição da biota em locais de referência e nos ambientes-alvo do monitoramento. A concepção multimétrica, por outro lado, busca reduzir a complexidade dos dados e apresentá-los de uma forma simplificada, acessível inclusive a indivíduos não especializados na área.

Fica evidente, portanto, o interesse por mecanismos complementares ao monitoramento de sistemas aquáticos e à legislação ambiental, com vistas a torná-los mais robustos. Houve algumas importantes iniciativas nesse sentido como, por exemplo, a discussão de uma nova visão de enquadramento de corpos hídricos com metas progressivas e a proposta de estabelecimento de uma relação entre vazão e demanda bioquímica de oxigênio (DBO) por meio de curvas de permanência (BRITES et al, 2006, 2007; AMARO et al, 2008).

Nesse contexto, o principal objetivo desta pesquisa foi discutir o uso da análise probabilística de ocorrência de incompatibilidades entre a qualidade da água e o enquadramento legal dos sistemas aquáticos brasileiros como ferramenta complementar ao monitoramento corriqueiramente realizado nesses ambientes. Para isso, com caráter de estudo de caso, efetuou-se o monitoramento da qualidade da água do rio Pariquera-Açu ao longo do ano de 2007, no que concerne às seguintes variáveis: oxigênio dissolvido (OD), turbidez, fósforo total, nitrogênio amoniacal, nitrito, nitrato e clorofila-a. A partir dos resultados obtidos, foi efetuado o cálculo das probabilidades de ocorrência de inconformidade entre as concentrações observadas no rio e os respectivos limites, superiores ou inferiores, descritos na resolução CONAMA 357/05 (BRASIL, 2005) para ambientes aquáticos de Classe 2 (Tabela 1).

A avaliação das porcentagens de ocorrência de incompatibilidade entre os valores observados e aqueles preconizados para rios de Classe 2 certamente pode oferecer subsídios e servir de base para a estruturação de planos de manejo e para a implementação de ações voltadas à manutenção da qualidade ambiental, dos diversos usos a que a água se destina e à sustentabilidade dos recursos hídricos. Deve-se salientar que as curvas probabilísticas apresentadas representam um nível interessante de condensação das informações oriundas do monitoramento, podendo ser divulgadas com maior aceitabilidade, inclusive fora do meio científico. Ademais, certamente podem orientar os tomadores de decisão e facilitar a identificação de áreas prioritárias de ação do poder público e de aplicação da legislação ambiental vigente, o que, certamente, constitui uma contribuição significativa para a área de gestão dos recursos hídricos.

\section{Material e métodos}

\section{Área de estudo}

O rio Pariquera-Açu situa-se na bacia hidrográfica do rio Ribeira de Iguape, porção sul do Estado de São Paulo. Os principais sistemas 
aquáticos abrangidos pela área de estudo são os rios Jacupiranga, Jacupiranguinha, Guaraú e Pariquera-Açu. O rio Pariquera-Açu apresenta usos múltiplos, com destaque para o abastecimento público, irrigação de propriedades agrícolas, recreação e diluição de efluentes (de estação de tratamento de esgotos). Além disso, vale mencionar que as porcentagens das diferentes formas de uso e ocupação do solo na sub-bacia apresentam a seguinte distribuição, segundo Loures (2008) e Loures et al (2009): 30\% de florestas, 28\% de campos, $18 \%$ de áreas agrícolas, 13\% de pastos e gramíneas, 3\% de área urbana, $1 \%$ de água e $7 \%$ de outros (por exemplo, padrões não identificáveis pelas imagens de satélite).

Vale ressaltar que os rios Jacupiranga e Pariquera-Açu são tributários diretos do rio Ribeira de Iguape, principal curso de água da bacia. As atividades econômicas desenvolvidas na sub-bacia do rio Jacupiranga, na qual se situa o rio estudado, são a pecuária e a agricultura, com destaque para o cultivo de chá e banana. $\mathrm{O}$ vale do rio Ribeira de Iguape possui importância estratégica, já que é uma das regiões do Brasil que concentra maior parcela remanescente de Mata Atlântica (RESENDE, 2002). No entanto, a região apresenta uma série de problemas sociais, como evasão escolar, desnutrição, ausência de esgotamento sanitário e elevadas taxas de mortalidade infantil (CHABARIBERY et al, 2004).

\section{Monitoramento}

Foram escolhidos nove pontos de coleta ao longo do eixo longitudinal do rio Pariquera-Açu (Figura 1, Tabela 2), de modo a abranger locais de especial interesse como, por exemplo, a montante e a jusante do lançamento do efluente da estação de tratamento de esgoto (ETE). Amostras de água foram coletadas sub-superficialmente (cerca de $15 \mathrm{~cm}$ abaixo da superfície), armazenadas em garrafas plásticas e congeladas até as análises no Laboratório BIOTACE, da Escola de Engenharia de São Carlos da Universidade de São Paulo. Os métodos empregados para a quantificação ou medição de cada variável são apresentados na Tabela 3. Foram efetuadas, ao longo de 2007, campanhas amostrais com frequência trimestral, com três dias consecutivos de coleta em cada período: 17, 18 e 19 de janeiro, 25, 26 e 27 de abril, 25, 26 e 27 de julho e 20, 21 e 22 de outubro de 2007.

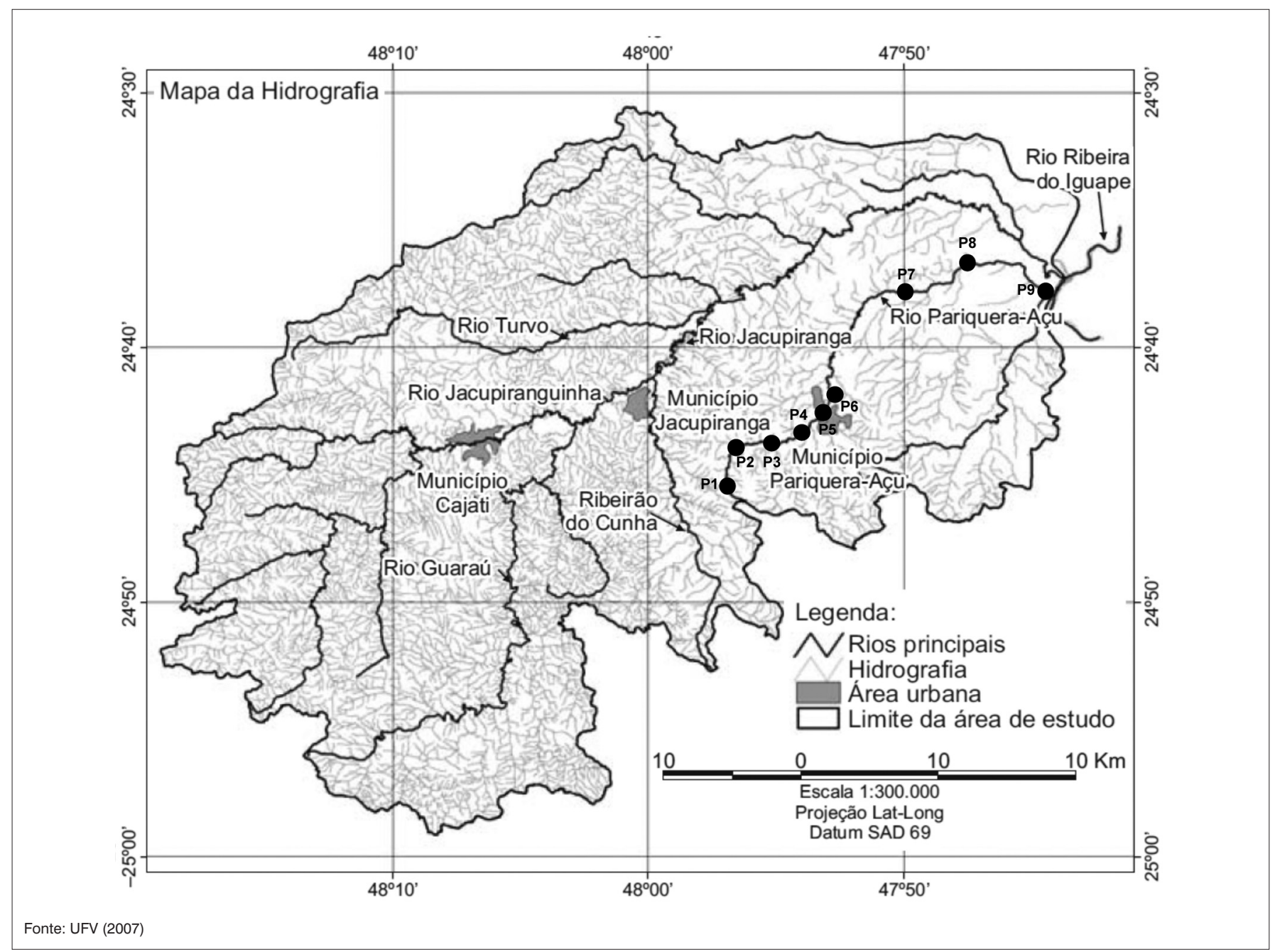

Figura 1 - Mapa hidrográfico da área de estudo, com destaque para os rios Jacupiranga, Jacupiranguinha, Guaraú e Pariquera-Açu. É destacada a localização aproximada dos pontos de coleta P1 a P9. 
Todas as análises foram realizadas com duas réplicas. As vazões do rio Pariquera-Açu foram medidas em P5, por meio do levantamento do perfil de velocidades (método do molinete), sendo determinadas pelo somatório do produto entre cada velocidade média e a sua área de influência, seguindo-se as recomendações de Pereira, Neto e Tucci (2003) e Studart (2003). Foi possível verificar a variação temporal das características químicas da água do rio Pariquera-Açu, já que foram efetuadas quatro coletas, abrangendo períodos com diferentes padrões de precipitação pluviométrica. Foram analisados, ainda, dados diários de chuva na área de estudo, obtidos de um posto meteorológico do CIIAGRO (CIIAGRO; IAC, 2007) situado no município de Pariquera-Açu.

\section{Curvas probabilísticas}

A partir dos resultados obtidos nas quatro coletas e nos nove pontos de coleta em três dias consecutivos, foram construídas as curvas de probabilidade de inconformidade de cada variável em relação ao estabelecido pelo seu enquadramento. Para isso, foi utilizada a

Tabela 2 - Coordenadas geográficas e referências de localização dos pontos de coleta de água no rio Pariquera-Açu

\begin{tabular}{|c|c|}
\hline Ponto de coleta & Localização e coordenadas geográficas \\
\hline \multirow{2}{*}{$\mathrm{P} 1$} & Próximo à nascente \\
\hline & $24^{\circ} 44^{\prime} 54^{\prime \prime} \mathrm{S}$ e $47^{\circ} 56^{\prime} 58^{\prime \prime} \mathrm{W}$ \\
\hline \multirow{2}{*}{ P2 } & Zona rural \\
\hline & $24^{\circ} 43^{\prime} 46^{\prime \prime}$ S e $47^{\circ} 56^{\prime} 28^{\prime \prime} \mathrm{W}$ \\
\hline \multirow{2}{*}{ P3 } & Antes do município de Pariquera-Açu \\
\hline & $24^{\circ} 43^{\prime} 36^{\prime \prime}$ S e $47^{\circ} 54^{\prime} 26^{\prime \prime} \mathrm{W}$ \\
\hline \multirow{2}{*}{ P4 } & Captação de água para abastecimento público \\
\hline & $24^{\circ} 43^{\prime} 00^{\prime \prime}$ S e $47^{\circ} 53^{\prime} 40^{\prime \prime} \mathrm{W}$ \\
\hline \multirow{2}{*}{ P5 } & Antes do lançamento da ETE \\
\hline & $24^{\circ} 42^{\prime} 07^{\prime \prime} \mathrm{S}$ e $47^{\circ} 52^{\prime} 55^{\prime \prime} \mathrm{W}$ \\
\hline \multirow{2}{*}{ P6 } & Depois do lançamento do efluente da ETE \\
\hline & $24^{\circ} 42^{\prime} 03^{\prime \prime} S$ e $47^{\circ} 52^{\prime} 55^{\prime \prime} \mathrm{W}$ \\
\hline \multirow{2}{*}{ P7 } & Depois do município de Pariquera-Açu \\
\hline & $24^{\circ} 37^{\prime} 57^{\prime \prime}$ S e $47^{\circ} 50^{\prime} 59^{\prime \prime} \mathrm{W}$ \\
\hline \multirow{2}{*}{ P8 } & Próximo ao Parque Estadual Campina do Encantado \\
\hline & $24^{\circ} 36^{\prime} 41^{\prime \prime}$ S e $47^{\circ} 46^{\prime} 38^{\prime \prime} \mathrm{W}$ \\
\hline \multirow{2}{*}{ P9 } & Foz do rio \\
\hline & $24^{\circ} 37^{\prime} 56^{\prime \prime}$ S e $47^{\circ} 44^{\prime} 12^{\prime \prime} \mathrm{W}$ \\
\hline
\end{tabular}

ETE: estação de tratamento de esgoto. função de distribuição acumulada, capaz de descrever a distribuição da probabilidade de uma variável aleatória de valor real X. Desse modo, o valor da função de distribuição acumulada $[\mathrm{F}(\mathrm{x})]$ é, para cada número real x, dada de acordo com a Equação 1 .

$F(x)=P(X \leq x)$

Equação 1

Nesse caso, $\mathrm{P}(\mathrm{X} \leq \mathrm{x})$ representa a probabilidade de que a variável $\mathrm{X}$ resulte em um valor inferior ou igual a $\mathrm{x}$. A probabilidade de interesse nesta pesquisa referiu-se, nos casos de não excedência ou de excedência, ao valor de $\mathrm{F}(\mathrm{x})$ para $\mathrm{x}$ igual ao padrão ambiental, para cada variável e considerando-se rios de Classe 2. Tal porcentagem representou, em termos práticos, a probabilidade de incompatibilidade com o enquadramento legal. Vale ressaltar que são apresentadas curvas de permanência por variável, mas com os resultados de todos os pontos de monitoramento. Em consonância com objetivo de cada pesquisa, essa estrutura pode ser repensada e as curvas, se for o caso, apresentadas individualmente para cada ponto de coleta.

\section{Resultados e discussão}

Os períodos nos quais houve campanhas amostrais no rio Pariquera-Açu foram caracterizados por diferentes lâminas mensais de precipitação pluviométrica. As lâminas totais de chuva para os meses de janeiro, abril, julho e outubro de 2007 foram de 274, 64, 149 e 40 mm, respectivamente (CIIAGRO; IAC 2007). Janeiro foi identificado como período chuvoso e outubro, por outro lado, foi caracterizado como mês de estiagem. Em julho, vale destacar que houve precipitação nos dias de coleta (inclusive nos dias anteriores), o que certamente influenciou os resultados de vazão do sistema aquático. Somente entre os dias 23 e 25 de julho, houve um total de 96 mm de chuva. As vazões médias do rio nos três dias consecutivos de cada coleta, medidas em P5, foram de 1,8, 0,02, 18,3 e 0,028 $\mathrm{m}^{3} \cdot \mathrm{s}^{-1}$, respectivamente para os meses de janeiro, abril, julho e outubro de 2007.

Além dos valores médios nos três dias consecutivos das coletas para cada variável (Figura 2), são apresentados boxplots construídos a partir de todos os dados obtidos nas quatro amostragens (Figura 3). É possível observar que, em relação ao $\mathrm{OD}$, as maiores concentrações

Tabela 3 - Métodos empregados para medição e quantificação das variáveis da água no rio Pariquera-Açu

$\begin{array}{lcc}\text { Variável } & \text { Técnica } & \text { Referência } \\ \text { Oxigênio dissolvido } & \text { Potenciométrica } & * \\ \text { Turbidez } & \text { Nefelométrica } & \text { ** } \\ \text { Fósforo total } & \text { Espectrofotométrica } & \text { APHA, AWWA, WEF (2005) } \\ \text { Nitrogênio amoniacal } & \text { Titulométrica } & \text { APHA, AWWA, WEF (2005) } \\ \text { Nitrito } & \text { Espectrofotométrica } & \text { APHA, AWWA, WEF (2005) } \\ \text { Nitrato } & \text { Espectrofotométrica } & \text { APHA, AWWA, WEF (2005) } \\ \text { Clorofila-a } & \text { Extração com etanol 80\% } & \text { (Nusch, 1980 - modificado de NEN, 1981) }\end{array}$

* Medição in situ realizada com multi-sonda Yellow Springs 556 ${ }^{\circledR}$; ** Medição realizada com turbidímetro Marconi ${ }^{\circledR}$ de bancada. 


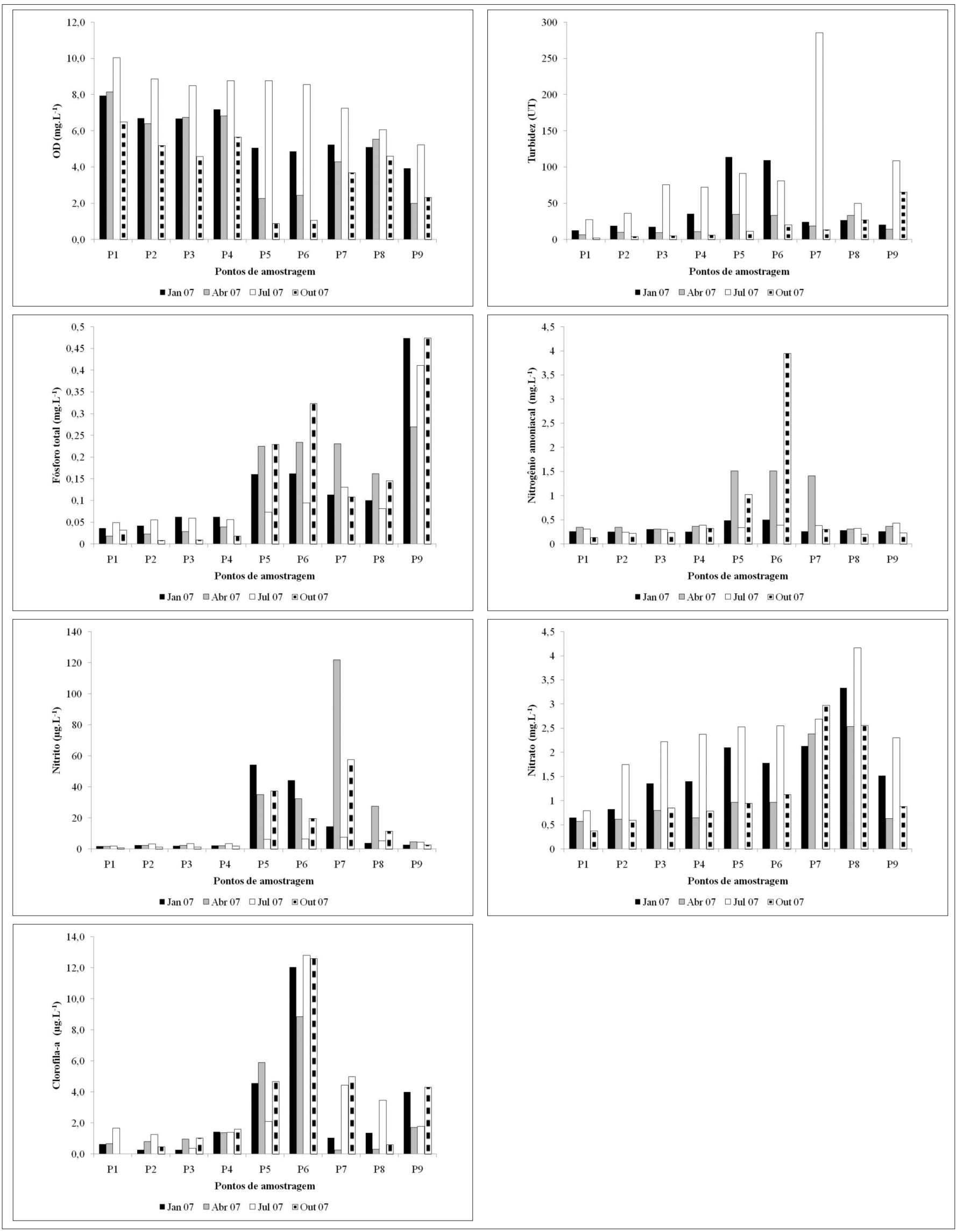

Figura 2 - Médias das variáveis da água do rio Pariquera-Açu nos três dias consecutivos das coletas de janeiro, abril, julho e outubro de 2007 nos nove pontos de amostragem. 

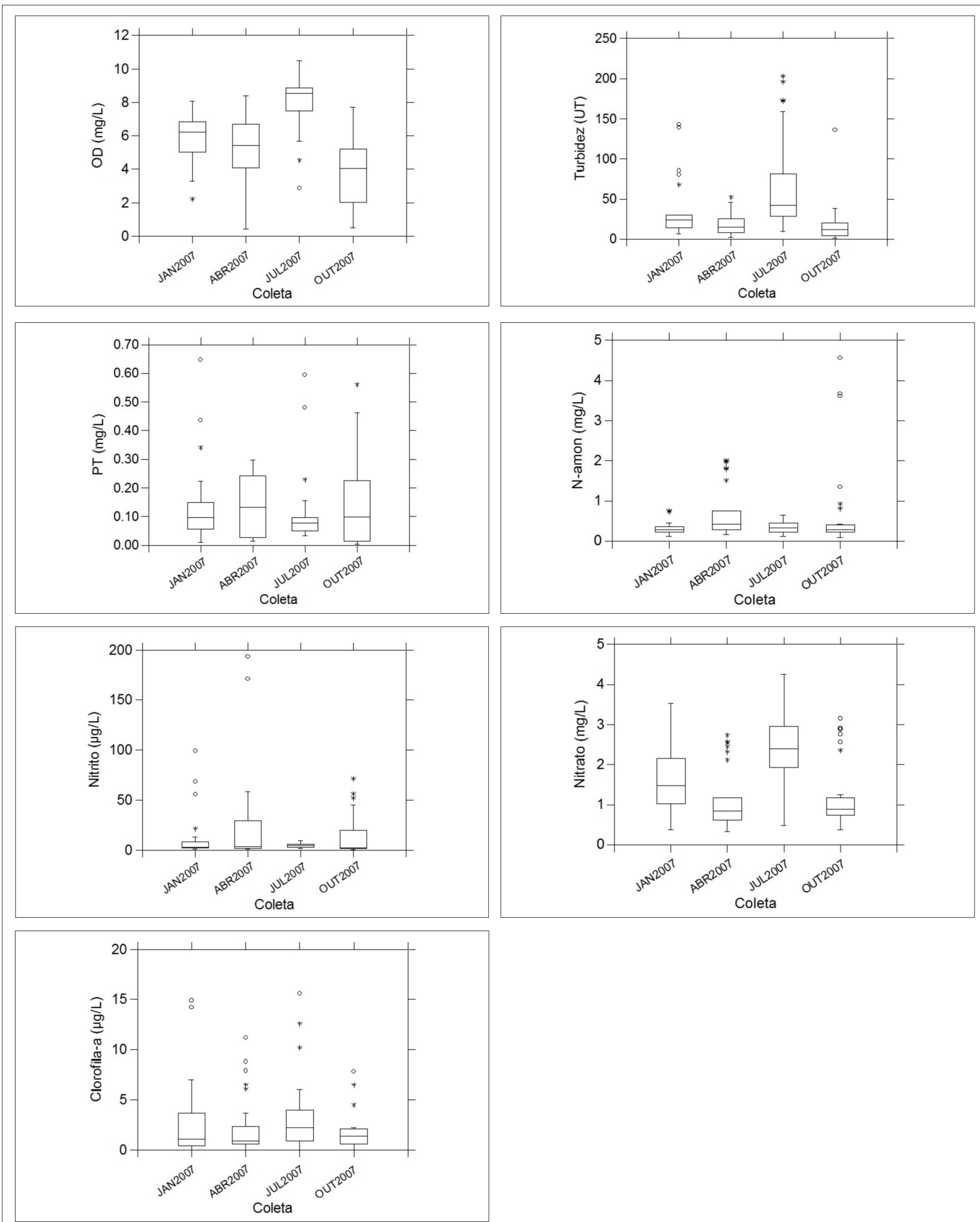

OD: oxigênio dissolvido; PT: fósforo total; $\mathrm{N}$-amon: nitrogênio amoniacal.

Figura 3 - Boxplots das variáveis da água do rio Pariquera-Açu, construídos a partir dos dados de todos os pontos de amostragem das coletas de janeiro (JAN), abril (ABR), julho (JUL) e outubro (OUT) de 2007. Os símbolos * $e^{\circ}$ denotam outliers. 
foram verificadas em julho (média de $8 \mathrm{mg} . \mathrm{L}^{-1}$ ), o que pode estar associado às menores temperaturas do ar e da água, que potencializam a solubilidade desse gás. Vale ressaltar, ainda, que os valores mínimos de $\mathrm{OD}$ foram detectados em P9, que corresponde à foz do rio Pariquera-Açu. Essa estação de coleta apresenta comportamento lêntico, em função do deságue no rio Ribeira de Iguape, que apresenta vazão significativamente superior. Isso favoreceu a proliferação de macrófitas aquáticas, cuja decomposição provavelmente contribuiu para o aumento na demanda de OD. Em outubro, concentrações próximas a $1 \mathrm{mg} \cdot \mathrm{L}^{-1}$ foram observadas em P5 e P6. Já as concentrações máximas (pico de $10 \mathrm{mg} . \mathrm{L}^{-1}$ em julho) foram encontradas em P1, que corresponde à nascente do sistema aquático.

Os valores de turbidez apresentaram significativa variação temporal, como pode ser observado no boxplot para essa variável (Figura 3) e estiveram associados à vazão medida nas diferentes coletas. Assim, em janeiro e julho, justamente quando as vazões foram maiores, foram observados os valores mais elevados de turbidez, com médias de 38 e 45 UT, respectivamente. Os valores mínimos foram observados em P1, em todas as coletas, e os máximos, em P5, P7 ou P9, dependendo do período. Esses pontos apresentam supressão de mata ciliar, o que pode ter contribuído para o arraste de material em suspensão para o interior da calha do rio, como resultado do escoamento superficial.

As médias das concentrações de fósforo total em todos os pontos no rio Pariquera-Açu foram inferiores a $0,15 \mathrm{mg} \cdot \mathrm{L}^{-1}$ nas quatro coletas (Figura 3). As concentrações mínimas foram detectadas em pontos de amostragem próximos à nascente do sistema (P1, P2 e P3), que são locais que ainda não apresentam impactos de caráter antrópico, visto que possuem proteção pela mata ciliar, não recebem efluentes domésticos e tampouco sofrem influência do município de Pariquera-Açu. As maiores concentrações de fósforo total (pico de 0,65 mg. $\mathrm{L}^{-1}$ ), por sua vez, foram observadas em P6 e P9. As elevadas concentrações em P9 foram associadas ao comportamento lêntico dessa estação amostral, que favorece a decomposição da biomassa vegetal e a liberação de nutrientes previamente imobilizados no sedimento, em caso de ocorrência de anoxia na interface água-sedimento. Em síntese, o comportamento lêntico facilitou a estratificação e a ocorrência de baixas concentrações de OD na interface, promovendo a liberação do nutriente (CALIJURI et al, 2008). Já P6 sofre influência do efluente da ETE de Pariquera-Açu, uma vez que se situa cerca de $100 \mathrm{~m}$ à jusante do ponto de lançamento. Essa ETE é composta por sistema de lagoas de estabilização que, de modo geral, não apresentam desempenho eficaz na remoção de nutrientes (OWENS e WALLING, 2002; NEAL et al, 2005; MIWA, FREIRE e CALIJURI, 2007). Assim, as concentrações de fósforo total encontradas em P6 (média máxima de 0,3 mg. $\mathrm{L}^{-1}$ em outubro) foram consequência do impacto do efluente da ETE sobre o rio.

O comportamento do nitrogênio amoniacal foi semelhante ao verificado para o fósforo total. As médias das concentrações dessa espécie, considerando-se todos os pontos, estiveram sempre abaixo de $1 \mathrm{mg} \cdot \mathrm{L}^{-1}$. As concentrações mínimas foram observadas novamente nos pontos de amostragem situados nas proximidades da nascente do rio e na zona rural do município (P1 e P2). As concentrações máximas (pico de 4,6 mg. $\mathrm{L}^{-1}$ em outubro) foram verificadas em P5, P6 e P9. O ponto P5, apesar de situar-se a montante do efluente da ETE, encontra-se em meio urbano e sofre, por essa razão, influência do município e de possíveis ligações clandestinas de esgoto doméstico.

As concentrações de nitrito e nitrato oscilaram entre $<25 \mu \mathrm{g}$. $\mathrm{L}^{-1}$ (P1, P2, P3, P4 e P9) e $122 \mu$ g.L.-1 (P7) e entre 0,4 mg.L-1 (P1) e 4,2 $\mathrm{mg} . \mathrm{L}^{-1}$ (P8), respectivamente. Os valores máximos dessas variáveis foram observados, majoritariamente, em P7 ou em P8, que se localizam a jusante de P6. Isso pode indicar a autodepuração que ocorre no curso de água. Os resultados sugeriram que o efluente da ETE contribui para o enriquecimento do sistema aquático, ou seja, para o incremento das concentrações de nutrientes verificado em P6. A presença de nitrito e nitrato nos pontos de amostragem subsequentes (P7 e P8) pode indicar que as concentrações de nitrogênio amoniacal foram, em parte, assimiladas pelo rio por meio da conversão a nitrito e nitrato (processo de nitrificação).

Por fim, as concentrações de clorofila-a, cujos valores médios não superaram $5 \mu \mathrm{g} . \mathrm{L}^{-1}$, considerando-se todos os pontos de coleta, estiveram associadas, espacialmente, à disponibilidade de luz e nutrientes. Os valores mínimos foram detectados em pontos próximos à nascente do rio, que apresentam vegetação ciliar e, portanto, são sombreados e recebem menor incidência direta de radiação solar. Os valores máximos foram observados, em sua maioria, em P6, o que pode estar associado à maior disponibilidade de fósforo e nitrogênio.

A Figura 4 apresenta as curvas de probabilidade amostral de excedência (ou de não excedência, no caso do OD) das variáveis estudadas, sem a distinção entre as diferentes coletas. Assim, as curvas foram construídas com base na função de distribuição acumulada, por meio da reunião de todos os dados disponíveis, referentes às quatro amostragens. O número de dados utilizados na análise foi significativo e é indicado para cada variável. No caso das curvas de permanência, quanto maior o número de dados, mais próxima da realidade será a probabilidade resultante e menos suscetível à interferência de valores extremos (outliers) estará a análise.

Ao longo de 2007, caracterizado pelas quatro campanhas amostrais efetuadas, a probabilidade de não excedência de $5 \mathrm{mg} \cdot \mathrm{L}^{-1}$ de OD no rio Pariquera-Açu, ou seja, de ocorrência de desacordo com a resolução CONAMA 357/05, foi de cerca de 35\%. As baixas concentrações de OD principalmente em P6 e P9 concorreram para que fosse encontrada essa porcentagem relativamente alta. Já para a turbidez, a probabilidade de excedência do limite superior estabelecido pela resolução supramencionada foi de apenas $8 \%$, o que indica que, ao longo de 2007, a ocorrência de conflitos com o enquadramento legal desse ambiente aquático em relação a essa variável apresentou probabilidade relativamente pequena. Contrariamente, no que se 


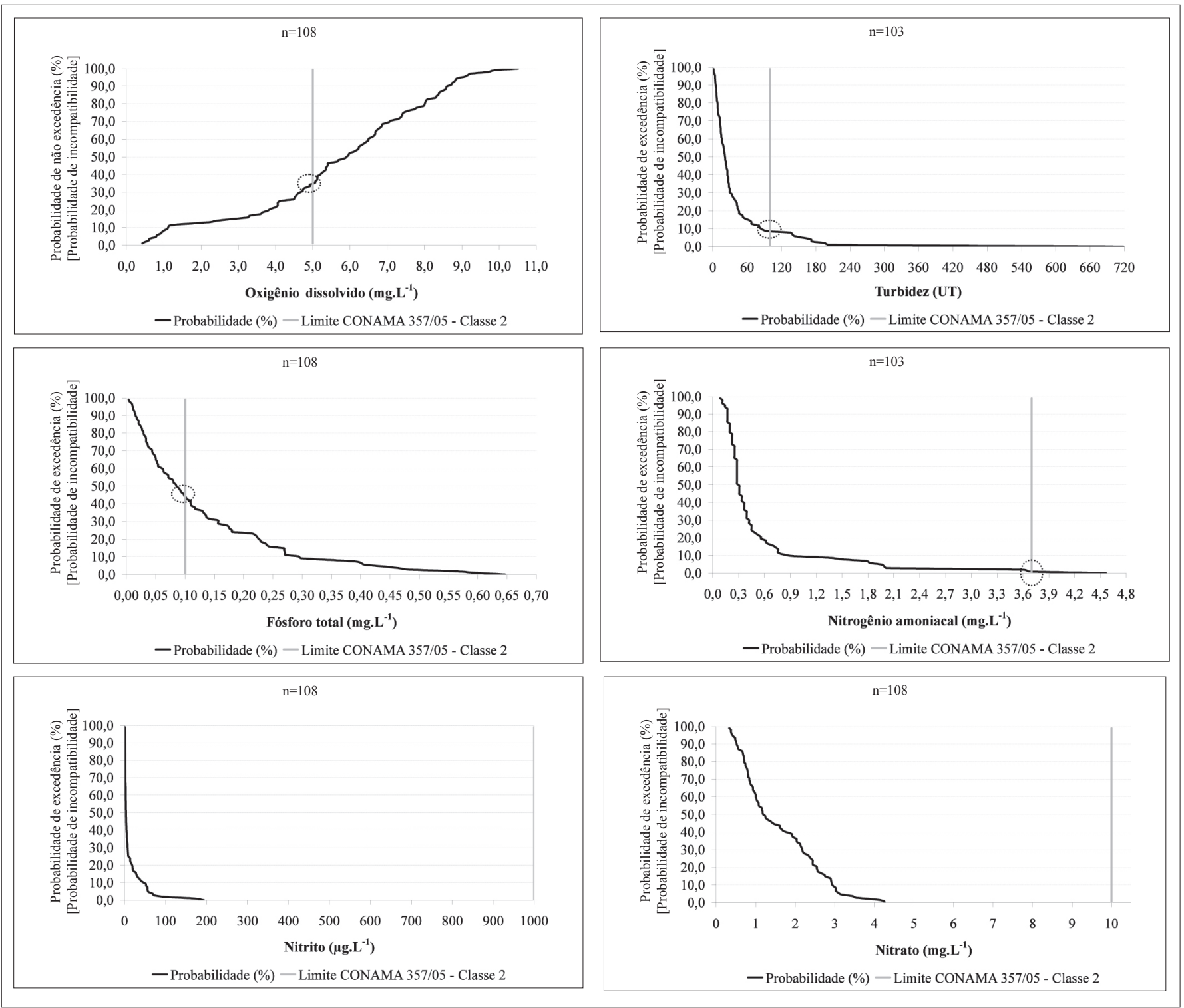

Figura 4 - Curvas de probabilidade de excedência ou não excedência (no caso do oxigênio dissolvido) das concentrações e valores das variáveis da água do rio Pariquera-Açu. É apresentado, para cada caso, o número n de dados que compuseram a análise probabilística.

refere ao fósforo total, a probabilidade de desacordo com as concentrações limite para Classe 2 foi elevada, 44\%. Contribuíram para isso as concentrações de fósforo total em P6 e P9. A probabilidade de inconformidade com o limite para o nitrogênio amoniacal foi baixa, $1 \%$. Em relação às variáveis nitrito, nitrato e clorofila-a, as respectivas probabilidades resultaram nulas.

Por questões de espaço, são apresentadas as curvas de permanência por variável e para todos os pontos de coleta no rio PariqueraAçu, indistintamente. Entretanto, considerando-se que os desvios padrão são significativos em relação às médias, quando comparados todos os pontos entre si, seria interessante construir as curvas probabilísticas por ponto de amostragem. Portanto, cabe ao usuário das curvas avaliar o objetivo principal de sua pesquisa e, a partir dessa reflexão, escolher o modo de agrupamento dos dados e o número final de curvas de probabilidade geradas. Caso o interesse principal seja a avaliação da componente espacial do monitoramento, sem dúvida a elaboração de curvas por ponto de amostragem é fundamental. Por outro lado, se o foco do trabalho é a questão temporal, pode ser desejável separar os dados por coleta e, a partir daí, determinar em quais períodos a situação do sistema aquático foi mais crítica em termos probabilísticos, ou seja, em qual época do ano o ambiente teve maior risco de apresentar incompatibilidade com seu enquadramento legal. Por fim, se a ideia é buscar uma visão geral do rio estudado, é válida a abordagem por variável e para todos os pontos de amostragem, como foi realizado para o rio Pariquera-Açu.

O impacto do uso das curvas de permanência pode estender-se para a legislação ambiental. Não se pode descartar o emprego dessas curvas com caráter complementar ao enquadramento dos sistemas 
aquáticos. Futuras pesquisas devem analisar a viabilidade de estabelecimento de probabilidades máximas de excedência (ou não excedência) ao longo do tempo, em vez considerar apenas concentrações fixas de natureza superior ou inferior. Isso poderia garantir uma flexibilidade desejável ao enquadramento e favorecer o estabelecimento de metas para melhoria paulatina e ininterrupta da qualidade da água, cuja importância é destacada por Calijuri, Cunha e Povinelli (2010).

A partir das curvas obtidas e da análise probabilística efetuada no estudo de caso, eventuais ações de recuperação ambiental do rio Pariquera-Açu devem principiar pela adequação do sistema de tratamento de esgotos gerados no município, visando à diminuição da carga afluente de nutrientes ao sistema aquático, carga esta detectada pelos resultados obtidos nas amostras de água de P6. Essas concentrações foram identificadas como as principais responsáveis pela obtenção de probabilidades elevadas de incompatibilidade com os valores estipulados para rios de Classe 2, sobretudo para OD e fósforo total. Outro ponto crítico do rio é o P9, embora seja importante considerar, nesse caso, o regime lêntico característico dessa estação amostral. A menor velocidade da água favoreceu o processo de sedimentação e a proliferação de macrófitas aquáticas, o que provavelmente contribuiu para as elevadas concentrações de fósforo total, os maiores valores de turbidez e as baixas concentrações de OD. Sugere-se especial atenção a esse ponto, que contribui diretamente para o rio Ribeira de Iguape, principal corpo de água da bacia. Deve ser mantido um acompanhamento da evolução do grau de trofia dessa porção do rio, para avaliar a contribuição relativa que o rio Pariquera-Açu oferece para o enriquecimento do rio Ribeira de Iguape.

\section{Conclusões e recomendações}

O emprego das curvas probabilísticas como ferramenta complementar ao monitoramento da qualidade da água de rios - utilizandose o rio Pariquera-Açu, Vale do Ribeira de Iguape, São Paulo, como estudo de caso - permitiu que fossem estabelecidas as seguintes conclusões e recomendações:

i A construção de curvas de probabilidade de incompatibilidade da qualidade da água de determinado ambiente aquático com seu respectivo enquadramento legal constitui uma ferramenta útil para o tratamento dos dados brutos gerados em programas de monitoramento. Por representarem um nível interessante de condensação de informações, as curvas probabilísticas podem orientar o poder público no processo decisório, facilitar o gerenciamento integrado da água em uma bacia hidrográfica e, ainda, favorecer a divulgação dos resultados para a sociedade. A utilização das curvas de probabilidade, portanto, pode ter impacto positivo significativo no gerenciamento dos recursos hídricos.
Os próximos esforços na área devem ser voltados à análise da viabilidade de utilizá-las de maneira complementar à legislação ambiental. Assim, o estabelecimento de uma probabilidade máxima tolerável de excedência de determinada concentração de uma variável da água pode contribuir para maior eficácia do monitoramento dos sistemas aquáticos, sobretudo daqueles em que se processam usos múltiplos. Essa forma alternativa de enquadramento pode ser mais adequada ao se tratar de ambientes que apresentam significativa heterogeneidade espacial e variabilidade temporal;

ii Ao longo de 2007, caracterizado por meio das quatro coletas efetuadas, as curvas de probabilidade construídas permitiram observar que as variáveis da água mais críticas no rio Pariquera-Açu, em conflito com os limites estabelecidos pela resolução CONAMA 357/05 para ambientes de Classe 2, foram fósforo total e oxigênio dissolvido;

iii Com vistas à redução da probabilidade de conflitos com o enquadramento legal do rio, detectada pelo estudo de caso da presente pesquisa, recomenda-se o aprimoramento do processo de tratamento de esgotos do município, visando à remoção adicional de nutrientes. Isso possibilitaria a minimização dos episódios de depleção de oxigênio dissolvido e de incremento excessivo de fósforo, além de contribuir para a inibição do aumento do estado trófico do ambiente aquático. Recomenda-se, também, a recomposição da mata ciliar ao longo de alguns trechos do ambiente aquático e a continuidade do monitoramento da qualidade da água do rio Pariquera-Açu, em especial de P9, situado na foz do sistema, já que se trata de um tributário direto do rio Ribeira de Iguape, principal rio da bacia hidrográfica estudada;

iv Sugere-se, ainda, que futuros planos de monitoramento incluam a construção de curvas de probabilidade de conflito com o enquadramento legal dos sistemas aquáticos. Isso pode servir para indicar a necessidade de ações prioritárias para melhorar a qualidade da água em relação a alguma variável (caso a probabilidade de inconformidade resulte elevada) ou, por outro lado, eliminar algumas variáveis do programa de monitoramento (ou diminuir sua frequência de medição ou quantificação), se for o caso, quando sua respectiva probabilidade de inconformidade resultar nula ou relativamente baixa ao longo do tempo.

\section{Agradecimentos}

Os autores gostariam de expressar sinceros agradecimentos à Fundação de Amparo à Pesquisa do Estado de São Paulo (FAPESP) pelo apoio financeiro (processos 2002/13449-1 e 2006/53550-4). Além disso, nossa gratidão ao Engenheiro Doron Grull, que contribuiu com a discussão do uso das curvas de permanência, e aos pareceristas anônimos pelas suas valiosas sugestões. 


\section{Referências}

AMARO, C.A. et al. Estudo Preliminar de um Índice de Conformidade ao Enquadramento de Corpos Hídricos. In: II Simpósio de Recursos Hídricos do Sul-Sudeste, Rio de Janeiro, 2008.

APHA, AWWA,WEF. Standard methods for the examination of water and wastewater. 21. ed. Washington: APHA, AWWA, WEF, 2005.

ARAÚJO, F.G. Adaptação do índice de integridade biótica usando a comunidade de peixes para o rio Paraíba do Sul. Revista Brasileira de Biologia, v. 58, n. 4, p. 547-558, 1998.

BRASIL. Conselho Nacional de Meio Ambiente. Resolução No 357, de 17 de março de 2005. 2005. Disponível em: <www.mma.gov.br/port/ conama/res/res05/res35705.pdf>. Acesso em: 8 maio 2009.

Lei $n^{\circ}$ 9433, de 8 de janeiro de 1997: Política Nacional dos Recursos Hídricos. 1997. Disponível em: <http://www.planalto.gov.br/ ccivil_03/Leis/L9433.htm>. Acesso em: 8 maio 2009.

BRITES, A.P.Z. et al. Metodologia para Implantação das Metas Progressivas para o Enquadramento dos Corpos d'Água. In: Workshop sobre Gestão Estratégica de Recursos Hídricos, 2006, Brasília - DF. Workshop - Gestão Estratégica de Recursos Hídricos, p. 1-4, 2006.

BRITES, A.P.Z.; PORTO, M.F.A.; FERNANDES, C.V.S. Proposta de uma Ferramenta de Auxílio para Aplicação do Enquadramento dos Corpos d'Água. In: XVII Simpósio Brasilerio de Recursos Hídricos, São Paulo, 2007.

CALIJURI, M.C.; CUNHA, D.G.F.; POVINELLI, J. Sustentabilidade: um desafio na gestão dos recursos hídricos. São Carlos: EESC/USP, 2010.

CALIJURI, M.C. et al. Nutrients and chlorophyll-a concentrations in tropical rivers of Ribeira do Iguape Basin, SP, Brazil. Acta Limnologica Brasiliensia, v. 20, n. 2, p. 131-138, 2008.

CHABARIBERY, D. et al. Desenvolvimento sustentável da Bacia do Ribeira de Iguape: diagnóstico das condições socioeconômicas e tipificação dos municípios. Informações Econômicas, v. 34, n. 9, p. 5789, 2004

CENTRO INTEGRADO DE INFORMAÇÕES AGROMETEOROLÓGICAS (ClIAGRO); Instituto Agronômico de Campinas (IAC). Balanço Hídrico da região do Vale do Ribeira, 2007. 2007. Disponível em: < http://ciiagro.iac. sp.gov.br/ciiagroonline >. Acesso em: 1 abr. 2007.

CLEMENT, L.; THAS, O. Estimating and Modeling Spatio-Temporal Correlation Structures for River Monitoring Networks. Journal of Agricultural, Biological, and Environmental Statistics, v. 12, n. 2, p. 161-176, 2007.

GROPPO, J.D. Estudo de tendências nas séries temporais de qualidade de água de rios do Estado de São Paulo com diferentes graus de intervenção antrópica. Dissertação (Mestrado em Ecologia de Agroecossistemas). Universidade de São Paulo, Piracicaba, 2005.
LOURES, S.S.P. Ambientes, uso e ocupação do solo e zoneamento estratégico para as sub-bacias dos rios Jacupiranga e PariqueraAçu, Vale do Ribeira, SP. Tese (Doutorado em Geotecnia Ambiental), Universidade Federal de Viçosa, Viçosa, 2008

LOURES, S.S.P. et al. Abordagem geoambiental para planejamento em regiões tropicais - estudo de caso: Vale do Ribeira de Iguape SP. In: CALIJURI, M.C.; MIWA, A.C.P.; FALCO, P.B. Subsídios para a sustentabilidade dos recursos hídricos: um estudo de caso em subbacias do Baixo Ribeira de Iguape, São Paulo, Brasil. São Carlos: EESC/ USP, 2009, p. 33-52.

MIWA, A.C.P.; FREIRE, R.H.F.; CALIJURI, M.C. Dinâmica de nitrogênio em um sistema de lagoas de estabilização na região do Vale do Ribeira (São Paulo - Brasil). Revista Engenharia Sanitária e Ambiental, v. 12, n. 2, p. 169-180, 2007

NEAL, C. et al. Water quality of treated sewage effluent in a rural area of the upper Thames Basin, southern England, and the impacts of such effluents on riverine phosphorus concentrations. Journal of Hydrology, $v$. 304, 1-4, p. 103-117, 2005

Nederlandse Norm (NEN). NEN 6520. Norma holandesa sobre determinação de clorofila a pelo método do etanol, 1981.

NORRIS, R.H.; HAWKINS, C.P. Monitoring river health. Hydrobiologia, v. 435, n. 1-3, p. 5-17, 2000.

$\mathrm{NUSCH}$, E.A. Comparison of different methods for chlorophyll and phaeopigment determination. Arch. Hydrobiologie., v. 14, p. 14-36, 1980

OWENS, P.N.; WALLING, D.E. The phosphorus content of fluvial sediment in rural and industrialized river basins. Water Research, v. 36, 3, p. 685701, 2002

PEREIRA, R.S.; Silva NETO, A.; TUCCI, C.E.M. Princípios da hidrometria. 2003. Disponível em: <http://www.iph.ufrgs.br/posgrad/disciplinas/ hip01/Cap13-Hidrometria.pdf > . Acesso em: 2 set. 2009.

RESENDE, R.U. As regras do jogo: legislação florestal e desenvolvimento sustentável no Vale do Ribeira. São Paulo: Annablume, FAPESP, 2002

STUDART, T.M.C. Escoamento superficial. 2003. Disponível em: <http:// www.deha.ufc.br/ticiana/hidrologia/apostila.htm>. Acesso em: $20 \mathrm{fev}$ 2007.

UNIVERSIDADE FEDERAL DE VIÇOSA (UFV). Mapa elaborado pela Universidade Federal de Viçosa, UFV, para o Projeto Temático FAPESP 02/13449-1. EESC/USP, FAPESP, 2007.

YABE, M.J.S.; OLIVEIRA, E. Metais pesados em águas superficiais como estratégia de caracterização de bacias hidrográficas. Química Nova, v. 21, n. 5 , p. 551-556, 1998 